\title{
Следы импактных событий в архее Побужского гранулито-гнейсового комплекса Украинского щита
}

\author{
Лобач-Жученко С.Б. ${ }^{1}$, Каулина Т.В. ${ }^{2}$, Егорова Ю.С. ${ }^{1}$ \\ ${ }^{1}$ Институт геологии и геохронологии докембрия PAH, Санкт-Петербург, slobach-zhuchenko@mail.ru \\ ${ }^{2}$ Геологический институт КНЦ РАН, Anamuтbl, kaulina@geoksc.apatity.ru
}

Аннотация. Анализ геологии, геохронологии и геохимии Побужского комплекса Украинского щита выявил ряд особенностей его строении и состава: многократность процессов в одной точке и отсутствие корреляции событий для соседних участков за исключением этапов са 3.6 и 2.8-2.7 млрд лет; поле «эндербитов» представляет собой тектоно-магматическую брекчию (смесь с мафическими гранулитами); геохимические характеристики многочисленных ультрамафитов и единичных жильных «гранитов» сходны с таковыми импактных расплавов. Полученные данные позволяют предполагать, что возникновение всех перечисленных особенностей Побужского комплекса связано с падением болидов.

Ключевые слова: Архей, тектоно-магматическая брекчия, импактный расплав, U-Pb возраст, Украинский щит.

\section{Impact traces in the Archean Bug granulite complex of the Ukrainian Shield}

\author{
Lobach-Zhuchenko S.B. ${ }^{1}$, Kaulina T.V. ${ }^{2}$, Egorova Yu.S. ${ }^{1}$ \\ ${ }^{1}$ Institute of Precambrian geology and geochronology, Sain-Petersburg, Slobach-zhuchenko@mail.ru \\ ${ }^{2}$ Geological Institute of the Kola Science Centre of RAS, Apatity, kaulina@geoksc.apatity.ru
}

\begin{abstract}
Analysis of geology, geochronology and geochemistry of the Bug complex of the Ukrainian Shield revealed a number of features of its structure and composition: multiple processes at one point and the absence of correlation of events for neighboring areas, with the exception of stages ca 3.6 and 2.8-2.7 Ga; the «enderbite» field is a tectonic-magmatic breccia (mixture with mafic granulites); geochemical characteristics of the numerous ultramafites and single "granite" veins are similar to those of impact melts. The data obtained, suggest that the occurrence of all the listed features of the Bug complex is associated with the fall of bolides.
\end{abstract}

Key words: Archean, tectono-magmatic breccia, impact melt, U-Pb age, Ukrainian Shield.

\section{Введение}

Значение ударов метеоритов для геологии раннего докембрия продемонстрировано многими исследователями. Корреляция во времени импактов и плюмов (Abbot, Isley, 2002) дали основание рассматривать удары метеоритов в качестве триггеров появления многих плюмов и последующего магматизма, в том числе Больших Изверженных Провинций (Jones et al., 2002). Значительная эрозия раннего докембрия, наряду с многократными структурно-метаморфическими процессами, связанными с эндогенной и экзогенной тектоникой, привели к исчезновению многих черт ранних импактных структур. Несмотря на это, разработанные в последние десятилетия методы позволили выделить ряд раннедокембрийских импактных структур и отметить многочисленность импактных событий в интервале времени 3.47-2.65 млрд. лет (Byerly et al., 2002 и др.).

Побужский гранулитовый комплекс (ПГК) Украинского щита (УЩ), располагается в Днестровско-Бугской провинции (юго-запад УЩ), состоит из разновозрастных интрузивных и супракрустальных пород, сформированных в интервале времени от 3.77 до 1.9 млрд. лет. Древнейшие породы комплекса обнажены на юго-востоке, на большей территории породы ПГК частично закрыты интрузиями протерозойских гранитов. Гранитогнейсы окружены поясами круто залегающих пород палеоархейской днестровско-бугской и неоархейской бугской серий (рис. 1 б в Балтыбаев и др., 2014). Отличается от соседних районов повышенным магнитным и гравитационным полями (Кислюк и др., 2011). 


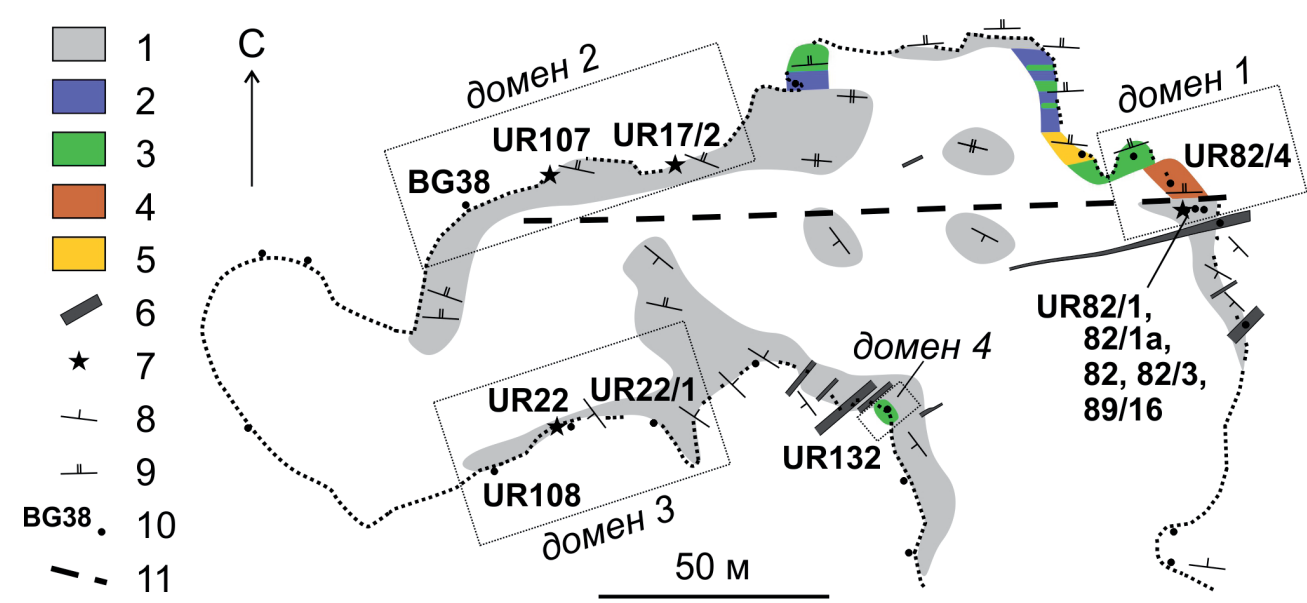

Рис. 1. Схематическая геологическая карта северной части карьера Одесский и положение доменов, описанных в тексте. 1 - гнейсоэндербиты с небольшими включениями мафических гранулитов, 2-4 - мафические гранулиты: 2 - ультраосновного и 3-4 - основного состава: 3 - метатолеиты, 4 - высоко железистые метабазальты, 5 - метаосадки, 6 - дайки метатрахиандезитобазальтов, 7 - включения ультрамафитов, 8-9 - элементы залегания: $8-\mathrm{S}_{\mathrm{n}+1}+\mathrm{S}_{\mathrm{n}+2}, 9-\mathrm{S}_{\mathrm{n}+3}, 10$ - места отбора и номера проб, 11 - южная граница зоны пластических деформаций.

Fig. 1. Schematic geological map of the northern part of the Odessa quarry and location of the domains described in the text. 1 - gneissic enderbites with small inclusions of mafic granulites; 2-4 - mafic granulites: 2 - ultrabasic and 3-4 - basic composition: 3 - meta tholeiitic basalts, 4 - meta ferro-basalts; 5 - metasediments; 6 - dykes of metatrachyandesibasalts; 7 - ultramafic inclusions; 8-9 - structural elements: $8-\mathrm{S}_{\mathrm{n}+1}+\mathrm{S}_{\mathrm{n}+2}, 9-\mathrm{S}_{\mathrm{n}+3}, 10-$ outcrop locations and sample numbers; 11 - south boundary of the zone plastic deformation.

Юго-восточная часть БГК (Голованевский домен) содержит более 60 интрузий, относящихся к гипербазитовой и дунит-перидотит-габбро-норитовой формациям. Аналогичные ультрамафиты располагаются и вне Голованевского домена, в центре поля гранитоидов (Кислюк и др., 2011).

\section{Краткая геологическая характеристика строения доменов севера Одесского карьера}

Карьер Одесский вскрывает ПГК на площади более 40000 м², сложен гнейсоэндербитами (далее - эндербиты), содержащими многочисленные включения мафитов и ультрамафитов. Размеры включений варьируют от первых десятков метров до десятков сантиметров. Благодаря включениям мафических гранулитов с возрастом 3.6 млрд. лет (Лобач-Жученко и др., 2019) и ультрамафитов, находящихся в более древних эндербитах (3.75 млрд. лет, Claesson et al., 2014), карьер в целом представляет собой тектоно-магматическую брекчию. Гетерогенность строения карьера можно видеть при сравнении доменов, расположенных в первых десятках метров друг от друга (рис. 1), а в таблице 1 дана последовательность процессов на этих территориях.

В домене 1 мафические гранулиты (северная часть домена) тектонически граничат с эндербитами (рис. 1). Породы домена находятся в зоне пластических деформаций с крутой субширотной сланцеватостью $\left(\mathrm{S}_{\mathrm{n}+3}\right)$ и крутой линейностью (Лобач-Жученко и др., 2018). Эндербиты содержат включения раздробленных и частично ассимилированных мафитов (UR82, UR82/3, UR89/16), бла-

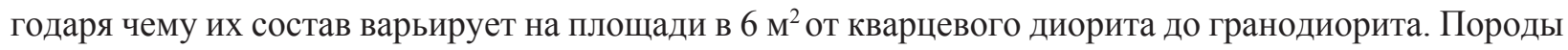
сильно разгнейсованы, местами имеет место мигматизация, которая проявлена и в наиболее крупном включении мафического гранулита (UR89/16).

Домен 2. Сложен эндербитами, содержащими включение ортопироксенита UR107 и фрагмент деформированной дайки Phl-гарцбургита UR17/2. Оба тела ультрамафитов разлинзованы, частично метаморфизованы. Наиболее сильная сланцеватость обусловлена расположением в той же зоне субширотных пластических деформаций $\left(\mathrm{S}_{\mathrm{n}+3}\right)$, что и домен 1.

Домен 3. В эндербитах (UR108, UR22/1) располагается крупное включение гарцбургита (UR22). На эндербиты и гарцбургит наложена гнейсовидность $\left(\mathrm{S}_{\mathrm{n}+2}\right) \mathrm{C} 3$ ориентировки; включение рассечено двумя дайками, идентичными по составу мафическим гранулитам домена 1 и жилой «гранита». 
Таблица 1. Последовательность и корреляция геологических процессов в доменах северной части Одесского карьера (Побужский гранулитовый комплекс, Украинский щит).

Table 1. Sequence and correlation of geological processes in the domains of the northern part of the Odessa quarry (the Bug complex of the Ukrainian Shield).

\begin{tabular}{|c|c|c|c|c|c|c|c|}
\hline \multicolumn{5}{|c|}{ ДОМЕН 1} & \multirow{3}{*}{$\begin{array}{c}\text { домЕН } 2 \\
\begin{array}{l}\text { Пироксенит/ } \\
\text { гарцбургит/ } \\
\text { эндербит }\end{array} \\
\text { UR107, } \\
\text { UR17/2, } \\
\text { BG038 } \\
\end{array}$} & \multirow{3}{*}{\begin{tabular}{|c|} 
домЕн 3 \\
$\begin{array}{c}\text { Гарцбургит/ } \\
\text { эндербиты }\end{array}$ \\
$\begin{array}{c}\text { UR22, } \\
\text { UR22/1, } \\
\text { UR108 }\end{array}$ \\
\end{tabular}} & \multirow{3}{*}{\begin{tabular}{|c|} 
дОМЕН 4 \\
$\begin{array}{c}\text { Мафический } \\
\text { гранулит/ } \\
\text { трахибазальт }\end{array}$ \\
UR132 \\
\end{tabular}} \\
\hline $\begin{array}{c}\text { Вмещающие } \\
\text { эндербиты }\end{array}$ & \multicolumn{2}{|c|}{$\begin{array}{c}\text { Включения } \\
\text { мафитов }\end{array}$} & \multicolumn{2}{|c|}{ Мафические гранулиты } & & & \\
\hline \multirow[t]{2}{*}{$\begin{array}{l}\text { UR82/1, } \\
\text { UR82/1a, } \\
\text { UR82/15 }\end{array}$} & UR82 & UR82/3 & UR89/16 & UR82/4 & & & \\
\hline & & & & & $\square 3750^{*}$ & & $3738 \pm 45^{* *}$ \\
\hline $3622 \pm 14$ & & $3670 \pm 5 * *$ & $3659 \pm 19$ & & $\square 3650$ & $3670 \pm 11$ & $3659 \pm 19$ \\
\hline $3573 \pm 19$ & & & & & & $3648 \pm 32$ & $3588 \pm 7$ \\
\hline $3498 \pm 47$ & $3499 \pm 72$ & & & & & & \\
\hline \multicolumn{8}{|l|}{$3441 \pm 68$} \\
\hline & & & & & $3334 \pm 70$ & & \\
\hline & & $3224 \pm 98$ & & & & & \\
\hline \multicolumn{8}{|l|}{$3104 \pm 9$} \\
\hline \multicolumn{8}{|l|}{$3103 \pm 5$} \\
\hline \multicolumn{8}{|l|}{$3064 \pm 6$} \\
\hline \multirow[t]{3}{*}{$3044 \pm 47$} & & $2900 \pm 260^{*}$ & & $2989 \pm 66$ & & & \\
\hline & & & $2845 \pm 65$ & & $2864 \pm 9$ & $2867+/-16$ & \\
\hline & & & & & $2814 \pm 51$ & & \\
\hline \multirow[t]{2}{*}{$2730 \pm 29$} & & $2742 \pm 23$ & & & $\square 2800-2700$ & & \\
\hline & & 2541 & & & & & $\square 2500$ \\
\hline $2096 \pm 52$ & $2172 \pm 30$ & & & $2013 \pm 3^{\text {Sm-Nd }}$ & $2077 \pm 33$ & $2080 \pm 23$ & $\square 2100$ \\
\hline \multirow[t]{2}{*}{$2027 \pm 36$} & & & & & $2046 \pm 29$ & & \\
\hline & & & & & $\square 2000-1900$ & 2015 & \\
\hline $1988 \pm 4$ & & & & & & $1980 \pm 30$ & $1988 \pm 4$ \\
\hline
\end{tabular}

Примечание. Возрасты рассчитаны на основе U-Th-Pb изотопных данных (циркон, метод SHRIMP II); Sm-Nd $-\mathrm{Sm}-\mathrm{Nd}$ изохронный метод (WR-Grn). Цвета: розовый - эндербиты, рыжий - лейкосома в эндербитах, голубой - интрузивные ультрамафиты: светлый - основного, темный - ультраосновного состава, зеленый - мафические гранулиты (метабазальты); черный шрифт - магматический возраст, красный - метаморфический, курсив - циркон с высоким содержанием U; * протолит эндербита (тоналит?), ** ксеногенные зерна циркона из гранитоидного источника.

Домен 4. Гранулит UR132 сохраняет наиболее раннюю сланцеватость: $\left(\mathrm{S}_{\mathrm{n}+1}\right.$ : С $\left.0^{\circ} \rightarrow 3<77\right)$, которая по мере удаления от точки 132 меняет простирание на $\mathrm{C} 3\left(\mathrm{~S}_{\mathrm{n}+2}\right)$ параллельно с изменением состава до эндербита (Fig. 3 In Lobach-Zhuchenko et al., 2017). Протолитом гранулита была вулканическая или гипабиссальная порода, испытавшая несколько этапов гранулитового метаморфизма. Гранулит рассечен дайкой метатрахибазальта, метаморфизованного в гранулитовой фации (табл. 1) (Lobach-Zhuchenko et al., 2017).

Гетерогенность состава цирконов и отсутствие корреляции процессов особенно характерны для интервала: от 3.6 до 2.8-2.75 млрд. лет. В петрографически сходных включениях ортопироксе- 
нитов UR82 и UR82/3 (домен 1) находятся цирконы разного состава и генезиса не только в разных включениях, но и в одном включении. B UR82/3 присутствует циркон с высоким Th/U и низким U/ $\mathrm{Yb}$ отношением, обычный для основных пород, и высокоурановый циркон, типичный для кислых магм и, вероятно, унаследованный из вмещающих эндербитов. UR82 не имеет зерен циркона с высоким $\mathrm{Th} / \mathrm{U}$ отношением, содержит много мелких округлых розовых зерен, типичных для гранулитов, много субконкордантных цирконов, датирующих процессы 2.8-2.7 млрд лет. Из сопоставления возраста и состава циркона различных доменов (табл. 1) следует, что породы, разделенные первыми десятками метров, существенно различны, демонстрируя гетерогенность строения и эволюции.

\section{Особенности состава ультрамафитов}

Важной особенностью состава ультрамафитов ПГК: интрузий Голованевского домена и небольших включений в эндербитах является пониженная магнезиальность, равная \#mg 0.86-0.80 в сравнении с примитивной мантией, ксенолитами мантии в кимберлитах кратонов и щелочных базальтах, абиссальными перидотитами, которых \#mg 0.89-0.90. Подобной низкой магнезиальностью обладают ультрамафиты импактного происхождения, расположенные в ядре структуры Вредефорт в Южной Африке (Hart et al., 1990) (рис. 2 a). Изменение отношения $\mathrm{FeO} / \mathrm{MgO}$ в процессе формирования импактных расплавов демонстрируют аккреционные бомбы из астроблемы Попигай с обломками пород мишени состава ТТГ, окруженными каймой стекла, которое в сравнении с ТТГ мишени имеет пониженное содержание $\mathrm{SiO}_{2}$ и пониженную \#mg (Kettrub et al., 2003). Другой особенностью ультрамафитов Побужского комплекса является высокое содержание в них $\mathrm{Ni}$ и для части пород высокое отношение $\mathrm{Ni} / \mathrm{Cr}$, превышающее таковое земных пород (рис. 2 б). Значительная часть интрузий Голованевского домена имеет отношение $\mathrm{Ni} / \mathrm{Cr}$, варьирующее от 0.9 до 4.4. Phl-гарцбургит $\mathrm{UR} 17 / 2$ - фрагмент деформированной дайки Одесского карьера - имеет $\mathrm{Ni} / \mathrm{Cr} \sim 4$, что отвечает таковому в хондритах. Повышенными отношениями $\mathrm{Ni} / \mathrm{Cr}$ обладают и ультрамафиты импактного происхождения структуры Вредефорт (рис. 2 б).

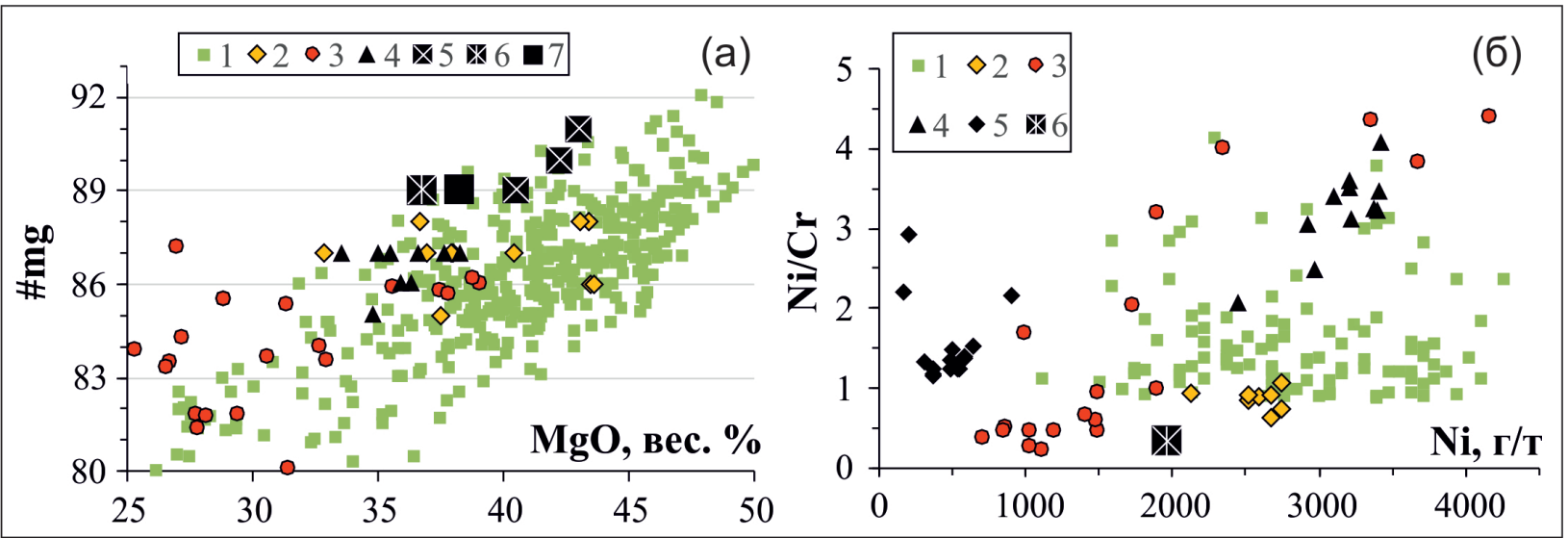

Рис. 2. (а) Соотношение \#mg и $\mathrm{MgO}$ в ультрамафитах ПГК: 1 - Голованевского домена, 2 - Немировской интрузии (Цымбал и др., 1996), 3 - включений в эндербитах (Лобач-Жученко и др., 2018), 4 - структуры Вредефорт (Hart et al., 1990), 5 - средний состав ксенолитов перидотитов верхней мантии Байкало-Монгольской области (Никитина и др., 2010), 6 - верхняя мантия (Palme, O`Neil, 2014), 7 - деплетированная мантия (Salters, Stracke, 2004). (б) Содержание Ni и Ni/Cr отношение в ультрамафитах ПГК. Знаки 1-4 и 6 - те же, что на рис. (a), 5 - импактные расплавы структуры Мороквенг (Andreoli et al., 1999).

Fig. 2. (a) $\mathrm{MgO}$ vs \#mg of PGC ultramafic rocks from: 1 - Golovanevskyy domain; 2 - Nemirovskaya intrusion (Tzymbal et al., 1996); 3 - enclaves within enderbites (Lobach-Zhuchenko et al., 2018); 4 - Vredefort structure (Hart et al., 1990); 5 - average composition of peridotitic xenoliths, upper mantle, Bajkal-Mongolia area (Nikitina et al., 2010); 6 - Upper Mantle (Palme, O`Neil, 2014), 7 - depleted mantle (Salters, Stracke, 2004). (b) The Ni abundance and ratio Ni/Cr in PGC ultramafic rocks from: 1-4 and 6 - as in Fig. (a), 7 - impact melts of Morokweng impact structure (Andreoli et al., 1999). 
Особенности составов импактных расплавов связаны с особенностями плавления при высоких Р-Т параметрах при ударе болида: селективным испарением элементов. Установлено селективное испарение $\mathrm{Fe}$ и $\mathrm{Mg}$ в зависимости от температуры (Яковлев и др., 2011), а повышенные содержания Ni могут быть связаны с различными процессами, в том числе с составом ударника (Яковлев и др., 1991).

\section{Особенности состава и структуры эндербитов}

Важной особенностью эндербитов ПГК является неоднородность состава, как это отмечено для домена 1, определяемая ассимиляцией мафических пород, главным образом гранулитов (метавулканитов). Ассимиляция более молодых метавулканитов (3.66 млрд. лет) более древними тоналиттрондьемитами (3.75 млрд. лет) возможна только при очень высоких температурах, которые в момент удара в центрах импактных структур превышают $2500^{\circ} \mathrm{C}$. Эксперименты по имитации ударов метеоритов и составы многих импактных расплавов демонстрируют увеличение К и отношения $\mathrm{K} / \mathrm{Na}$ и ряд других особенностей при плавлении (Koeberl et al., 2012). Архейские трондьемиты $\left(\mathrm{SiO}_{2}-69.56\right.$ вес. \% и $\mathrm{K}_{2} \mathrm{O}-2.89$ вес. \%) - породы мишени импактной структуры Вредефорт - под влиянием удара протерозойского болида испытали частичное плавление с образованием «гранофелсов», которые содержат меньше $\mathrm{SiO}_{2}\left(53.23\right.$ вес. \%), больше $\mathrm{Al}_{2} \mathrm{O}_{3}\left(28.53\right.$ вес. \%), и $\mathrm{K}_{2} \mathrm{O}(5.75$ вес. \%) в сравнении с трондьемитами (Lana et al., 2004). Уменьшение содержания $\mathrm{SiO}_{2}$ в продуктах частичного плавления трондьемита невозможно в условиях РТ параметров обычного ультраметаморфизма, что указывает на принципиально иные условия при частичном плавлении при импакте. В Одесском карьере сходный с «гранофелсом» Вредефорт необычный состав имеет жила «гранита», секущая контакт ТTГ и включения перидотита UR22 (домен 3): $\mathrm{SiO}_{2}-61.17, \mathrm{Al}_{2} \mathrm{O}_{3}-20.26, \mathrm{~K}_{2} \mathrm{O}-11.44$ вес. \%. Гранитоиды мишени импактной структуры Вредефорт испытали перекристаллизацию с уменьшением размера зерен (Lana et al., 2004). Для эндербитов Одесского карьера также характерны размеры зерен $<1$ мм. Следует отметить, что в эндербитах, расположенных $\sim$ в 30 км к ЮВ от Одесского карьера (Кашаро-Александровский карьер), развита сеть тонких жил псевдотахилитов, возможно, импактного происхождения.

\section{Обсуждение}

Анализ установленных особенностей строения и состава пород ПГК позволяет предполагать, что они обусловлены импактными событиями: 3.6 и 2.8-2.7 млрд. лет. В результате раннего падения болида ( 3.6 млрд. лет) имел место гранулитовый метаморфизм, с которым связано образование эндербитов за счет пород ТТГ состава, гранулитовый метаморфизм вулканитов и формирование тектоно-магматической брекчии. Циркон эндербитов имеет низкое $\mathrm{Th} / \mathrm{U}$ отношение (0.04-0.1), подчеркивающее его метаморфическое происхождение. Среди цирконов этого этапа присутствуют высокоурановые цирконы, имеющие Т кристаллизации $>800^{\circ} \mathrm{C}$. В эндербитах сохраняются более древние цирконы с U-Pb возрастом по ${ }^{207} \mathrm{~Pb} / 206 \mathrm{~Pb} 3.70-3.79$ млрд. лет (Лобач-Жученко и др., 2011; Бибикова и др., 2013; Claesson et al., 2014), который интерпретируется как первичный магматический возраст (Claesson et al., 2014).

Около 2.8-2.7 млрд. лет назад вероятно имел место другой импакт, активно проявленный на севере карьера, в доменах 1 и 2 (табл. 1), а также за пределами карьера. С этим событием связано внедрение и кристаллизация ультрамафитов Голованевского домена и дайки субщелочного гарцбургита UR17/2 с геохимическими чертами, сходными с импактными расплавами, формирование на севере карьера зоны тектоно-магматической брекчии в условиях повторного метаморфизма и мигматизции эндербитов. Совместный анализ состава и возраста циркона различных пород этой зоны (табл. 1) показывает, что в одно время кристаллизовались разные расплавы, которые потом были совмещены в одном образце.

Ударный метаморфизм этого этапа привел к существенной перестройке U-Pb системы циркона с возникновением тренда потери $\mathrm{Pb}$ древних цирконов (Abramov et al., 2011), идущего к значениям 2.8-2.7 млрд. лет, наблюдаемый в породах карьеров Одесский, Казачий Яр и Гайвороновский (Лобач-Жученко и др., 2011; Бибикова и др., 2013; Claesson et al., 2014; Shumlyansky et al., 2021). 
Корреляция цирконов (и процессов) в интервале времени между 3.6 и 2.8-2.7 млрд. лет отсутствует (табл. 1).

Палеопротерозойский этап (2.05-1.9 млрд. лет) выражен значительно слабее, чем этап 2.8-2.7 млрд. лет. Главным геологическим событием явилось внедрение даек трахиандезитобазальтов (рис. 1) и метабазальтов, кристаллизовавшихся в условиях гранулитового метаморфизма. Палеопротерозойский метаморфизм гранулитов (UR82/4, домен 1) не отразился на U-Pb системе циркона, возраст метаморфизма определен Sm-Nd методом (табл. 1). Южнее, в обн. UR82 (домен 1) наряду с перестройкой Sm-Nd системы имело место образование кайм на зернах циркона 2027-2096 млн. лет назад (табл. 1).

\section{Заключение}

Наблюдаемые особенности пород ПГК: строение территории, представляющее собой тектономагматическую брекчию с ассимиляцией основных пород, различная индивидуальная история включений, присутствие магматических пород с особенностями состава импактных расплавов, псевдотахилитовые жилы, многократность геологических событий, устанавливаемых в одном образце, позволяют предполагать, что они являются следствием импактов.

Работа выполнена в рамках темы НИР № FMNU-2019-0001.

\section{Литература}

1. Балтыбаев Ш.К., Лобач-Жученко С.Б., Балаганский В.В., Юрченко А.В., Егорова Ю.С., Богомолов Е.С. Возраст и метаморфизм кристаллосланцев побужского гранулитового комплекса Украинского щита - древнейших вулканитов фундамента Восточно-Европейской платформы // Региональная геология и металлогения. 2014. № 58. С. 33-44.

2. Бибикова Е.В., Клаэссон С., Федотова А.А., Степанюк Л.В., Шумлянский Л. Кирнозова Т.И., Фугзан М.М., Ильинский Л. Изотопно-геохронологическое (U-Th-Pb, Lu-Hf) изучение цирконов архейских магматических и метаосадочных пород Подольского домена Украинского щита // Геохимия. 2013. Т. 51. № 2. С. 99-121.

3. Кислюк В.В., Зюльцле В.В., Дорковська 3.М., Гук Л.В., Бондаренко В.В., Чернецька Г.Й., Нікіташ Л.П., Кислюк Г.В. Державна геологічна карта України. Масштаб 1:200 000. Центральноукраїнська серія. Аркуш М-35XXXVI (Гайворон). К. Изд-во: Міністерство екології та природних ресурсів України, Державна служба геології та надр України, Північне державне регіональне геологічне підприємство «Північгеологія». 2011. 116 с.

4. Лобач-Жученко С.Б., Степанюк Л.М., Пономаренко А.Н., Сергеев С.А., Пресняков С.Л. Возраст цирконов из эндербито-гнейсов Среднего Побужья (Днестрово-Бугский мегаблок Украинского щита) // Минерал. Сборник. Киев. 2011. Т. 33. №1. С. 3-15.

5. Лобач-Жученко С.Б., Каулина Т.В., Марин Ю.Б., Юрченко А.В., Скублов С.Г., Егорова Ю.С., Галанкина О.Л., Сергеев С.А. Палеоархейсеий U-Pb (SIMS SHRIMP II) возраст мафических гранулитов Побужского комплекса Украинского щита // Доклады РАН. 2019. Т. 484. Ч. 1. С. 101-104. https://doi.org/10.1134/ S1028334X19010240.

6. Лобач-Жученко С.Б., Егорова Ю.С., Балтыбаев Ш.К., Балаганский В.В., Степанюк Л.М., Юрченко А.В., Галанкина О.Л., Богомолов Е.С., Сукач В.В. Перидотиты в палеоархейских ортогнейсах Побужской гранулитогнейсовой области Украинского щита: геологическое положение, особенности состава, генезис // Эволюция вещественного и изотопного состава докембрийской литосферы. Ред. В.А. Глебовицкий, Ш.К. Балтыбаев. Санкт-Петербург. Издательско-полиграфическая ассоциация высших учебных заведений. 2018. С. 164-192.

7. Никитина Л.П., Гончаров А.Г., Салтыкова А.К., Бабушкина М.С. Окислительно-восстановительное состояние континентальной литосферной мантии Байкало-Монгольской области // Геохимия. 2010. № 1. C. $17-44$.

8. Ц Цымбал С.Н., Каневский В.Я., Кривдик С.Г. Ультрамафиты Немировской интрузии (Украинский щит) // Мин. журн. 1996. № 18. С. 35-47.

9. Яковлев О.И., Герасимов М.В., Диков Ю.П. Оценка температурных условий образования HASP- и GASP-стекол лунного реголита // Геохимия. 2011. № 3. С. 227-238.

10. Яковлев О.И., Бадюков Д.Д., Файнберг В.С., Баулин Н.Н., Пилюгин Н.Н., Тихомиров С.Г. Ударное взаимодействие железного метеорита с силикатной мишенью // Геохимия. 1991. № 6. С. 796-805.

11. Abbott D.H., Isley A. E. Extraterrestrial influences on mantle plume activity // Earth Planet. Sci. Lett. 2002. V. 205. P. 53-62.

12. Abramov O., Kring D. A., Mojzsis S. J. Modeling of impact-induced age resetting and partial Pb-loss in zircon grains // 42nd Lunar and Planetary Science Conference. 2011. 2674. 
13. Andreoli M. A. G., Ashwal L. D., Hart R. J., Huizenga J. M. A Ni- and PGE-enriched quartz norite impact melt complex in the Late Jurassic Morokweng impact structure, South Africa // Geol. Soc. America. Spec. Publ. 1999. V. 339. P. 91-108. https://doi.org/10.1130/0-8137-2339-6.91.

14. Byerly G.R., Lowe D.R., Wooden J.L., Xie X. An Archean impact layer from the Pilbara and Kaapvaal cratons // Science. 2002. V. 297. P. 1325-1327. https://doi.org/10.1126/science.1073934.

15. Claesson S., Bibikova E., Shumlyanskyy L.V., Dhuime B., Hawkesworth C.J. The oldest crust in the Ukrainian Shield - Eoarchaean U-Pb ages and Hf-Nd constraints from enderbites and metasediments // Geol. Soc. London. 2014. Spec. Publ. P. 227-259. https://doi.org/10.1144/SP389.9.

16. Hart R.J., Andreoli M.A.G., Smith C.B., Otter M.L., Durrheim R. Ultramafic rocks in the centre of the Vredefort structure (South Africa): Possible exposure of the upper mantle? // Chemical Geology. 1990. V. 83. P. 233-248.

17. Jones A.P., Price G.D., Price N.J., DeCarli P.S., Clegg R.A. Impact induced melting and the development of large igneous provinces // Earth and Planetary Science Letters. 2002. V. 202. P. 551- 561.

18. Kettrup B., Deutsch A., Masaitis V.L. Homogeneous impact melts produced by a heterogeneous target? Sr-Nd isotopic evidence from the Popigai crater, Russia // Geochimica et Cosmochimica Acta. 2003. V. 67. P. 733-750. https:// doi.org/10.1016/S0016-7037(02)01143-2.

19. Koeberl c., Claeys P., Hecht L., McDonald I. Geochemistry of Impactites // Elements. 2012. V. 8. P. $37-42$.

20. Kysliuk V.V., Zultsle V.V., Dorkovska Z.M., Guk L.V., Bondarenko V.V., Chernetska G.Y., Nikitash L.P., Kysliuk G.V. (2011). State Geological Map of Ukraine in the scale 1:200 000, Map sheet M-35-XXXVI (Haivoron). Ministry of Ecology and Natural Resources of Ukraine, Kyiv: State Geological Survey, Northern State Regional Geological Enterprise Pivnichgeologiya, p. 116 (In Ukrainian).

21. Lana C., Reimold W.U., Gibson R.L., Kjeberl C., Siegesmund S. Nature of the Archean midcrust in the core of the Vredefort Dome, Central Kaapvaal Craton, South Africa // Geochimica et Cosmochimica Acta. 2004. V. 68. No. 3. P. 623-642. https://doi.org/10.1016/S0016-7037(03)00447-2.

22. Lana C., Gibson R.L., Reimold W.U. Impact tectonics in the core of the Vredefort dome, South Africa: implications for central uplift formation in very large impact structures // Meteorit Planet. Sci. 2003. V. 38. P. 1093-1107.

23. Lobach-Zhuchenko S.B., Kaulina T.V., Baltybaev S.K., Balagansky V.V., Egorova Yu.S., Lokhov K.I., Skublov S.G., Sukach V.V., Bogomolov E.S., Stepanyuk L.M., Galankina O.L., Berezhnaya N.G., Kapitonov I.N., Antonov A.V., Sergeev S.A. The long (3.7-2.1 Ga) and multistage evolution of the Bug Granulite-Gneiss Complex, Ukrainian Shield, based on the SIMS U-Pb ages and geochemistry of zircons from a single sample // Geological Society London. Spec. Publ. 2017. V. 449. P. 175-206. https://doi.org/10.1144/SP449.3.

24. Palme H., O'Neill H.St.C. Cosmochemical Estimates of Mantle Composition // In: Treatise on Geochemistry. 2014. V. 2. P. 1-38.

25. Salters V.J.M., Stracke A. Composition of the depleted mantle // Geochemistry Geophysics Geosystems. 2004. An electronic journal of the Earth Sciences. V. 5. № 5. P. 13. 